\title{
Evidence for a QTL on chromosome 19 influencing LDL cholesterol levels in the general population
}

\author{
Marian Beekman*,1,12, Bastiaan T Heijmans ${ }^{1,12}$, Nicholas G Martin ${ }^{2}$, John B Whitfield ${ }^{3}$, \\ Nancy L Pedersen ${ }^{4}$, Ulf DeFaire ${ }^{5}$, Harold Snieder ${ }^{6,7}$, Nico Lakenberg ${ }^{1}$, H Eka D Suchiman ${ }^{1}$, \\ Peter de Knijff ${ }^{8}$, Rune R Frants ${ }^{8}$, Gert Jan B van Ommen ${ }^{8}$, Cornelis Kluft ${ }^{9}$, George P Vogler ${ }^{10}$, \\ Dorret I Boomsma ${ }^{11}$ and P Eline Slagboom ${ }^{1}$
}

\begin{abstract}
${ }^{1}$ Section of Molecular Epidemiology, Leiden University Medical Center, Leiden, The Netherlands; ${ }^{2}$ Queensland Institute for Medical Research, Brisbane, Australia; ${ }^{3}$ Department of Clinical Biochemistry, Royal Prince Alfred Hospital, Sydney, Australia; ${ }^{4}$ Department of Medical Epidemiology, Karolinska Institute, Stockholm, Sweden; ${ }^{5}$ Institute of Environmental Medicine, Karolinska Institute, Stockholm, Sweden; ${ }^{6}$ Twin Research \& Genetic Epidemiology Unit, St Thomas' Hospital, London, UK; ${ }^{7}$ Georgia Prevention Institute, Medical College of Georgia, Augusta, USA; ${ }^{8}$ Department of Human and Clinical Genetics, Leiden University Medical Center, Leiden, The Netherlands; ${ }^{9}$ Department of Vascular and Connective Tissue Research, TNO Prevention and Health, Leiden, The Netherlands; ${ }^{10}$ Department of Biobehavioral Health, Center for Developmental and Health Genetics, Pennsylvania State University, University Park, PA, USA; ${ }^{11}$ Department of Biological Psychology, Free University of Amsterdam, Amsterdam, The Netherlands
\end{abstract}

The genetic basis of cardiovascular disease (CVD) with its complex etiology is still largely elusive. Plasma levels of lipids and apolipoproteins are among the major quantitative risk factors for CVD and are well-established intermediate traits that may be more accessible to genetic dissection than clinical CVD end points. Chromosome 19 harbors multiple genes that have been suggested to play a role in lipid metabolism and previous studies indicated the presence of a quantitative trait locus (QTL) for cholesterol levels in genetic isolates. To establish the relevance of genetic variation at chromosome 19 for plasma levels of lipids and apolipoproteins in the general, out-bred Caucasian population, we performed a linkage study in four independent samples, including adolescent Dutch twins and adult Dutch, Swedish and Australian twins totaling 493 dizygotic twin pairs. The average spacing of short-tandem-repeat markers was $6-8 \mathrm{cM}$. In the three adult twin samples, we found consistent evidence for linkage of chromosome 19 with LDL cholesterol levels (maximum LOD scores of 4.5, 1.7 and 2.1 in the Dutch, Swedish and Australian sample, respectively); no indication for linkage was observed in the adolescent Dutch twin sample. The QTL effects in the three adult samples were not significantly different and a simultaneous analysis of the samples increased the maximum LOD score to 5.7 at $60 \mathrm{cM}$ pter. Bivariate analyses indicated that the putative LDL-C QTL also contributed to the variance in ApoB levels, consistent with the high genetic correlation between these phenotypes. Our study provides strong evidence for the presence of a QTL on chromosome 19 with a major effect on LDL-C plasma levels in outbred Caucasian populations. European Journal of Human Genetics (2003) 11, 845-850. doi:10.1038/sj.ejhg.5201053

Keywords: linkage; quantitative trait locus (QTL); cardiovascular risk factors; twin pairs

${ }^{*}$ Correspondence: Dr Marian Beekman, Section of Molecular Epidemiology, Leiden University Medical Center, PO Box 9503, 2300 RA, The Netherlands. Tel.: + 3171 5271914; Fax: + 3171 5271985;

E-mail: M.Beekman@lumc.nl

${ }^{12}$ These authors contributed equally to this work.

Received 19 December 2002; revised 22 April 2003; accepted 22 May 2003

\section{Introduction}

Dissecting the genetic basis of cardiovascular disease (CVD) is complicated by the etiologic heterogeneity of seemingly undistinguishable clinical end points. Major quantitative risk factors for CVD such as cholesterol levels may be more 
accessible to genetic dissection. ${ }^{1}$ Also, individuals do not need to be classified as affected or unaffected for these quantitative variables, which often leads to ambiguous or uncertain phenotype assignment. Genes described to date that play a role in lipid metabolism have mainly been identified in familial lipid disorders, many of which are monogenic diseases. For example, defects in the genes encoding the low-density-lipoprotein-receptor ( $L D L R$, $19 \mathrm{p} 13.2)^{2}$ and apolipoprotein B $(A P O B, 2 \mathrm{p} 24)^{3}$ are found to be responsible for the most common forms of familial hypercholesterolemia, and mutations in the $A B C 1$ gene (9q31.1), encoding the cholesterol efflux regulatory protein, induce familial HDL cholesterol deficiency (Tangier's disease). ${ }^{4}$ Although carriers of such mutations may develop severe disorders of lipid metabolism, these mutations explain only a minor proportion of the variation in plasma levels of lipids and apolipoproteins at the level of the general population. ${ }^{5}$ The results of twin studies showing that $50-80 \%$ of the population variation in levels of lipids and apolipoproteins is attributable to genetic factors ${ }^{6,7}$ thus imply that the majority of the genes determining these levels are still to be discovered.

Chromosome 19 harbors several genes that have been suggested to play a role in lipid metabolism including the $L D L R$ (19p13.2), ${ }^{2}$ the apolipoprotein E gene (APOE, $19 \mathrm{q} 13.2)^{8}$ and other genes from the APOE/C1/C4/C2 cluster, ${ }^{9,10}$ the insulin-receptor gene (INSR, 19p13.3), ${ }^{11}$ the hormone-sensitive-lipase gene (LIPE, 19q13.1) ${ }^{12}$ and the LDLR-related-protein-type3 gene (LRP3, 19q12). ${ }^{13}$ Compatible with this wealth of candidate genes, evidence for linkage with plasma levels of total cholesterol was found in Pima Indians and with LDL cholesterol levels in Hutterites. ${ }^{14,15}$ In contrast to the findings in these genetic isolates, however, no significant linkage with LDL-C levels on chromosome 19 was found in genome scans among outbred Caucasians. ${ }^{16-20}$ To gain insight into the effect of genetic variation on chromosome 19 on lipid metabolism in the general, Caucasian population, we performed a linkage study in four twin samples originating from The Netherlands, Sweden and Australia totaling 493 dizygotic twin pairs.

\section{Subjects and methods Subjects}

We studied samples of adolescent Dutch twins and adult Dutch (sample on cardiovascular risk factors), Swedish (Swedish Adoption/Twin Study of Aging) and Australian twins (Semi-Structured Assessment for the Genetics of Alcoholism). The recruitment of the twins and the measurements of lipid and apolipoprotein levels in the different samples are described elsewhere. ${ }^{7}$ In this study we used 83 dizygotic (DZ) young Dutch twin pairs (aged 13-22 years), 117 DZ adult Dutch twin pairs (aged 34-62 years), 44 DZ Swedish twin pairs (aged 42-81 years) and
249 DZ Australian twin pairs (aged 31-80 years). All relationships were confirmed with the Graphical Representation of Relationship software ${ }^{21}$ using more than 100 short tandem repeats. Total cholesterol, HDL cholesterol, apolipoprotein B, apolipoprotein AI, triglycerides and apolipoprotein E levels were assessed in the plasma. Concentrations of low-density lipoprotein (LDL) cholesterol were calculated according to Friedewald et al. ${ }^{22}$ If the triglyceride concentration did exceed $4.52 \mathrm{mmol} / \mathrm{l}$, the subject obtained a missing value for LDL cholesterol. ${ }^{23}$

\section{Genotyping}

In the four twin pair samples, 12 short tandem repeats with an average intermarker distance of 8 centiMorgans (cM) were genotyped (D19S247, D19S1034, D19S394, D19S714, D19S49, D19S433, D19S47, APOC2, D19S246, D19S180, D19S210 and D19S254). In the two Dutch samples, four additional markers were genotyped (D19S391, D19S865, D19S420, D19S178), resulting in an average spacing of $6 \mathrm{cM}$ in the Dutch. The average heterozygosity for these markers was estimated at 0.78 and the Marshfield genetic map (http://research.marshfieldclinic.org/genetics/) was used.

The Cy5-labeled PCR products were electrophoretically separated on an automated-fluorescence DNA sequencer, ALFexpress (Amersham Pharmacia Biotech). Analysis and assignment of the marker alleles were performed with Fragment Analyser 1.02 (Amersham Pharmacia Biotech). To reduce genotyping errors, one known genotype was present on each gel, $5 \%$ of the genotypings were repeated and two independent individuals performed the allele calling. SIBMED ${ }^{24}$ was used to identify unlikely double recombinants, the occurrence of which may be due to genotyping errors. After running SIBMED and checking the raw genotyping data, approximately $0.2 \%$ of the total genotypings appeared to be erroneous. Dependent on the error, these genotypes were changed in the right genotype or were set to missing.

\section{Statistical analysis}

Allele frequencies were estimated separately for the twin samples using marker data for all individuals. ${ }^{25}$ Plasma levels of triglycerides and apoE showed a skewed distribution and these values were therefore transformed by natural logarithm prior to analysis. The full distribution of multipoint identity-by-descent (IBD) sharing probabilities was estimated every centiMorgan across chromosome 19 using Genehunter 2.1. ${ }^{26}$ Linkage analysis of quantitative traits was performed with variance components analysis using structural equation modeling with maximum likelihood implemented in the software $\mathrm{Mx}$ $1.52 \mathrm{~d} .{ }^{27}$ The weighted likelihood approach, which makes use of the full distribution of IBD-probabilities, with adjustments for age and sex was used. ${ }^{28}$ In a four-sample simultaneous analysis, IBD status for the DZ pairs was 
estimated separately for each of the four samples in Genehunter $2.1^{26}$ using population-specific allele frequencies. Mean LDL-C levels, background genetic and nonshared environmental effects were estimated for each sample separately. The absolute QTL effects were constrained to be equal over the different samples. Heterogeneity between the effects of the QTL in the different twin samples was tested by comparing the model estimating all parameters for the populations separately with the model in which the QTL effect was constrained to be equal. Bivariate analyses ${ }^{29}$ were performed for correlated plasma levels of LDL-C and apoB.

\section{Results}

The characteristics of the adolescent Dutch and adult Dutch, Swedish and Australian dizygotic twins totaling 493 pairs are shown in Table 1.

The four twin samples were analyzed using variance components analyses, which revealed a consistent indication for linkage with LDL cholesterol (LDL-C) levels (Table 2). The maximum LOD scores (MLS) were 4.5, 1.7 and 2.1 in adult Dutch, Swedish and Australian twins, respectively; no linkage was observed in the adolescent Dutch twins. Lower levels of linkage were also observed for the LDL-C levels correlated phenotypes total cholesterol and apoB in the adult populations (Table 2).

As shown in Figure 1, linkage in the adult twins samples was observed in the same chromosomal region suggesting that the same QTL may be involved. This was reinforced by the fact that the QTL effect was not significantly different in the three adult populations at the positions where the MLS were observed $(P=0.50,34 \mathrm{cM}$ pter; $P=0.13,60 \mathrm{cM}$ pter; $P=0.06,63 \mathrm{cM}$ pter), whereas the QTL effect was significantly different in the adolescent Dutch population (eg $P=0.0001,60 \mathrm{cM}$ pter). Therefore, the adult populations were combined in one linkage analysis including 410 dizygotic twin pairs (Figure 1). This analysis increased the
MLS for LDL-C levels to 5.7 at $60 \mathrm{cM}$ pter. Of the twin pairs that individually contributed more than 0.20 to the MLS, $62 \%(18 / 29)$ were Dutch, 17\% (5/29) were Swedish and $21 \%(6 / 29)$ were Australian.

LDL-C and apoB levels are highly correlated phenotypes, both phenotypically $(\geqslant 0.79)$ and genetically $(\geqslant 0.79)$ (Table 3) indicating that genetic variation influencing LDL-C levels also influences apoB levels. Nevertheless, the MLSs were considerably higher for LDL-C levels than for apoB levels. To gain insight into the effect of the LDL-C QTL on apoB levels, we performed a bivariate linkage analysis of the two phenotypes at the position of MLS in the adult samples. Although the confidence intervals were wide and the estimates of the QTL effect not always significant (Table 3), this analysis showed that the putative QTL explained a considerable proportion of the variance in apoB levels in addition to that of LDL-C levels.

\section{Discussion}

We have studied chromosome 19 for linkage with intermediate lipid phenotypes of cardiovascular disease in dizygotic twin pairs from the general population of The Netherlands, Sweden and Australia. In all the adult twin samples, we found evidence for linkage of chromosome 19 with LDL-C levels with MLS ranging from 1.7 to 4.5 . In spite of a large heritability of LDL cholesterol levels, which was previously estimated in the adolescent and adult twin samples between 0.60 and $0.85,{ }^{7}$ no indication for linkage was observed in the adolescent twin sample. This may be due to partly different effects of genes on lipid levels at different ages as suggested by Snieder et $a l^{30}$ or to different gene-environment interaction on lipid levels at different ages as suggested by Zerba et $a l^{31}$ The size of the QTL effect on LDL-C levels was not significantly different in the adult samples and a simultaneous analysis of these adult samples increased the LOD score to 5.7 at $60 \mathrm{cM}$ from pter. This constitutes significant linkage according to the Lander-

Table 1 Characteristics of adolescent Dutch and adult Dutch, Swedish and Australian dizygotic twin samples

\begin{tabular}{|c|c|c|c|c|}
\hline \multirow[b]{2}{*}{ Phenotype } & \multirow{2}{*}{$\begin{array}{c}\text { Adolescent } \\
\text { Netherlands } \\
(n=166)\end{array}$} & \multicolumn{3}{|c|}{ Adult } \\
\hline & & $\begin{array}{c}\text { Netherlands } \\
(n=234)\end{array}$ & $\begin{array}{l}\text { Sweden } \\
(n=88)\end{array}$ & $\begin{array}{l}\text { Australia } \\
(n=498)\end{array}$ \\
\hline Men, \% & 49.4 & 48.7 & 59.1 & 35.7 \\
\hline Age, years - mean (range) & $17(13-22)$ & $44(34-59)$ & $65(42-81)$ & $44(31-80)$ \\
\hline Inter-marker distance, $\mathrm{CM}$ - mean (SD) & $6.29(4.18)$ & $6.29(4.18)$ & $8.38(4.02)$ & $8.38(4.02)$ \\
\hline Body mass index $\left(\mathrm{kg} / \mathrm{m}^{2}\right)$ & $20.28(2.21)$ & $24.64(3.06)$ & $25.21(3.07)$ & $25.44(5.19)$ \\
\hline LDL-C, mmol/I - mean (SD) & $2.56(0.65)$ & $3.63(0.99)$ & $4.26(1.07)$ & $3.37(1.07)$ \\
\hline ApoB, g/l - mean (SD) & $0.79(0.17)$ & $1.21(0.35)$ & $1.04(0.21)$ & $0.97(0.28)$ \\
\hline Total cholesterol, mmol/l - mean (SD) & $4.15(0.70)$ & $5.39(1.06)$ & $6.50(1.11)$ & $5.64(1.20)$ \\
\hline HDL-C, mmol/l - mean (SD) & $1.28(0.26)$ & $1.22(0.38)$ & $1.47(0.34)$ & $1.46(0.41)$ \\
\hline ApoAl, g/l - mean (SD) & $1.38(0.20)$ & $1.67(0.43)$ & $1.39(0.30)$ & $1.44(0.27)$ \\
\hline Triglycerides, mmol/l - mean (SD) & $0.68(0.30)$ & $1.22(0.71)$ & $1.62(0.87)$ & $1.90(1.69)$ \\
\hline ApoE, mg/dl - mean (SD) & $6.59(2.39)$ & $2.54(1.02)$ & $-(-)$ & $4.18(1.88)$ \\
\hline
\end{tabular}


Table 2 Maximum LOD scores observed at chromosome 19 for lipid and apolipoprotein levels in adolescent Dutch and adult Dutch, Swedish and Australian DZ twins

\begin{tabular}{lcc}
\hline Phenotype & Position from pter & Max $L O D$ score \\
\hline LDL cholesterol & & \\
Adolescent Netherlands & 98 & 0.5 \\
Adult Netherlands & 60 & 4.5 \\
Adult Sweden & 63 & 1.7 \\
Adult Australia & 34 & 2.1 \\
ApoB & & \\
Adolescent Netherlands & 98 & 0.3 \\
Adult Netherlands & 48 & 1.0 \\
Adult Sweden & 70 & 1.6 \\
Adult Australia & 80 & 0.5 \\
Total cholesterol & & \\
Adolescent Netherlands & 53 & 0.2 \\
Adult Netherlands & 60 & 2.3 \\
Adult Sweden & 63 & 1.3 \\
Adult Australia & 30 & 1.7 \\
HDL cholesterol & & 0.1 \\
Adolescent Netherlands & 67 & 0.5 \\
Adult Netherlands & 32 & 0.2 \\
Adult Sweden & 34 & 1.2 \\
Adult Australia & 57 & 0.1 \\
ApoA1 & & 0.2 \\
Adolescent Netherlands & 0 & 1.0 \\
Adult Netherlands & 34 & 1.5 \\
Adult Sweden & 36 & 1.2 \\
Adult Australia & 51 & 0.6 \\
Triglycerides & & 0.1 \\
Adolescent Netherlands & 52 & \\
Adult Netherlands & 45 & \\
Adult Sweden & 63 & \\
Adult Australia & 63 & \\
ApoE & & \\
Adolescent Netherlands & 69 & \\
Adult Netherlands & 63 & \\
Adult Sweden & & \\
Adult Australia & & \\
\hline & & \\
\hline
\end{tabular}

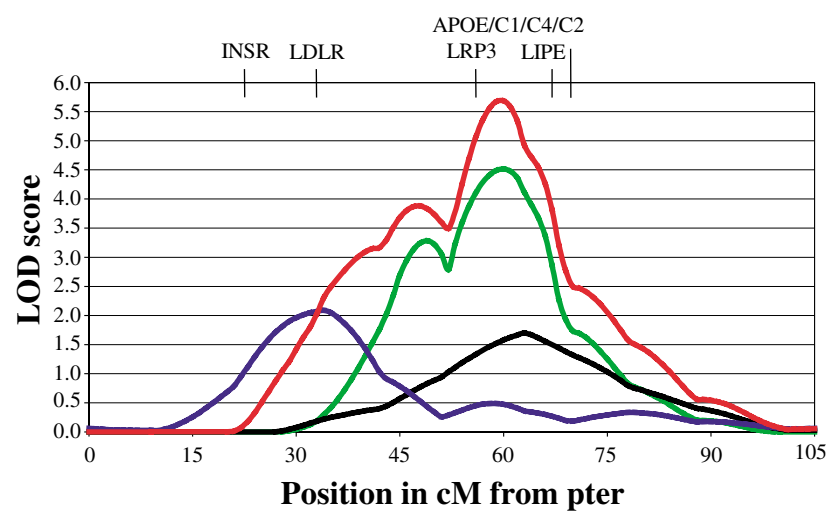

Figure 1 Linkage of LDL cholesterol levels with chromosome 19 in adult Dutch (green line), Swedish (black line) and Australian (blue line) twins in separate analyses and a combined analysis (red line).

Kruglyak criteria. $^{32} \mathrm{~A}$ bivariate analysis indicates that the QTL also influences apoB levels as is consistent with the fact that the majority of apoB protein circulates as a constituent of LDL particles. Our linkage study thus emphasizes the relevance of genetic variation on chromosome 19 for cardiovascular risk in the general population.

Previous studies reported evidence for linkage of chromosome 19 with total cholesterol levels (MLS = 3.89) and LDL-C levels (Genome-wide $P$-value $=0.035$ ) in Pima Indians $^{14}$ and Hutterites, ${ }^{15}$ respectively. Our study extends these findings in genetic isolates to the general, Caucasian population. A further inspection of other genome scans in Caucasians from the general population (Table 4) shows that, although the reported LOD scores for chromosome 19 are not significant, they are compatible with our findings. Linkage with $\mathrm{LDL}_{1}-\mathrm{C}$ levels in the San Antonio Heart Study $(\mathrm{LOD}=2.26)$ and with $\mathrm{LDL}_{2}-\mathrm{C}$ levels $(\mathrm{LOD}=1.86),{ }^{33}$ and linkage with total cholesterol levels in the Rochester Family Heart Study $(\mathrm{LOD}=1.14) .{ }^{34}$ No suggestion for linkage with total cholesterol or LDL-C levels, however, was found in selected samples of myocardial infarction patients, type II diabetes patients and patients with familial combined hyperlipidemia. ${ }^{16-20}$ The LDL-C QTL on chromosome 19 thus constitutes one of the most replicated result from linkage studies, virtually ruling out the possibility that it is a false-positive observation.

The region in which we and other groups (Figure 1, Table 4) found evidence for linkage is broad, as is a general characteristic of results from twin and sib pair studies. QTL mapping in Drosophila melanogaster and Saccharomyces cerevisiae demonstrated that linkage results at a broad chromosomal region may be caused by several polymorphisms with a relatively small effect, which could be interpreted as one gene with a major effect. ${ }^{35,36}$ Possibly, several loci on chromosome 19 are influencing LDL cholesterol levels and perhaps different loci play major roles in Australian and European LDL cholesterol levels, which might explain the different locations of the MLS. However, the overall effect size of these loci is the not significantly different in Dutch, Swedish and Australians. The main candidates for underlying the LDL-C QTL on chromosome 19 (Table 4) are the APOE/C1/C4/C2 gene cluster and the $L D L R$ and $L R P 3$ gene loci. Apolipoprotein E is the major constituent of chylomicrons, VLDL and IDL particles and serves as ligand for the LDLR. When VLDL and IDL are not efficiently removed from the circulation by the LDLR, LDL particles will accumulate. The LDLR is also known to play an important role in the clearance of apoBcarrying-lipoproteins by the liver. ${ }^{2,37}$ Apolipoprotein C1 is a constituent of VLDL and HDL particles. It inhibits the lipoprotein lipase (LPL)-mediated hydrolysis of the triglycerides from VLDL, which leads to lower levels of LDL-C. ${ }^{38}$ ApoC2 has the opposite effect on LDL-C levels, since it is an activator of LPL. ${ }^{39}$ Although the function of apoC4 is unknown, there are some indications that it might play a role in lipid metabolism. ${ }^{10,40}$ The LRP3 is a family member of the LDLR. It is also expressed in the liver and it binds apoE-containing particles. The function of the LRP3 
Table 3 Proportion of the total variance of LDL-C and ApoB explained by the putative QTL on the basis of bivariate analyses at the position of the maximum LOD score for LDL-C in the adult twin samples

\begin{tabular}{|c|c|c|c|c|c|c|}
\hline Twin sample & $\begin{array}{c}\text { Phenotypic correlation } \\
L D L-C / A p o B\end{array}$ & $\begin{array}{l}\text { Genetic correlation } \\
\text { LDL-C/ApoB }\end{array}$ & $\begin{array}{l}\text { Position } \\
\text { (cM) }\end{array}$ & & $V_{Q T L}{ }^{\mathrm{a}} / V_{\text {total }} \mathrm{b}^{\mathrm{b}}$ & $\begin{array}{c}\text { Proportion of variance } \\
\text { attributable to QTL }(95 \% \mathrm{Cl})\end{array}$ \\
\hline Adult Netherlands & 0.89 & 0.92 & 60 & LDL-C & $0.80 / 0.88$ & $0.92(0.71-0.98)$ \\
\hline Adult Sweden & 0.79 & 0.79 & 63 & $\begin{array}{l}\text { LDL-C } \\
\text { ApoB }\end{array}$ & $\begin{array}{l}0.94 / 1.15 \\
0.02 / 0.04\end{array}$ & $\begin{array}{l}0.84(0.11-0.98) \\
0.68(0.00-0.85)\end{array}$ \\
\hline Adult Australia & 0.83 & 0.92 & 34 & $\begin{array}{l}\text { LDL-C } \\
\text { ApoB }\end{array}$ & $\begin{array}{l}0.38 / 1.01 \\
0.01 / 0.07\end{array}$ & $\begin{array}{l}0.38(0.05-0.67) \\
0.12(0.00-0.38)\end{array}$ \\
\hline
\end{tabular}

${ }^{a}$ Variance explained by the QTL.

${ }^{\mathrm{b}}$ Total variance.

Table 4 Overview of studies indicating linkage of plasma levels of LDL cholesterol and related phenotypes on chromosome 19

\begin{tabular}{|c|c|c|c|c|}
\hline Phenotype & Population & $\begin{array}{c}\text { Location on chromosome } \\
19 \text { (CM) }\end{array}$ & $\begin{array}{l}\text { Genome-wide P-value (Gwp) } \\
\text { or maximum LOD score (MLS) }\end{array}$ & Reference \\
\hline \multirow{4}{*}{ LDL cholesterol } & Dutch & 60 & $M L S=4.5$ & This study \\
\hline & Sweden & 63 & $M L S=1.7$ & This study \\
\hline & Australian & 34 & $M L S=2.1$ & This study \\
\hline & Above combined & 60 & $\mathrm{MLS}=5.7$ & This study \\
\hline LDL cholesterol & Hutterites & 52 & $G w p=0.035$ & \\
\hline Total cholesterol & Pima Indians & 21 & $\mathrm{MLS}=3.9$ & 14 \\
\hline $\mathrm{LDL}_{1}$ cholesterol & Mexican & 38 & $\mathrm{MLS}=2.4$ & 33 \\
\hline $\mathrm{LDL}_{2}$ cholesterol & $\begin{array}{l}\text { Mexican } \\
\text { Americans }\end{array}$ & 62 & $\mathrm{MLS}=1.9$ & 33 \\
\hline Total cholesterol & $\begin{array}{l}\text { Non-Hispanic } \\
\text { whites }\end{array}$ & 27 & $\mathrm{MLS}=1.1$ & 34 \\
\hline
\end{tabular}

remains unclear, but as a family member of LDLR a role in lipid metabolism is assumed. ${ }^{13}$ INSR and LIPE are candidates for influencing triglyceride levels, but not for LDL-C levels. ${ }^{11,12}$ Near the LDLR locus, the ATHS locus has been mapped involved in atherogenic lipoprotein phenotype pattern $\mathrm{B}$, which is characterized by small, dense LDL particles, increased levels of triglycerides and decreased levels of HDL-C. ${ }^{41}$ Since we have no indication for linkage with levels of triglycerides and HDL-C, we assume that the ATHS locus is a different locus than our LDL-C QTL.

In conclusion, we report strong and significant evidence for the presence of genetic variation at chromosome 19 with a major effect on LDL-C plasma levels in outbred Caucasian populations. Since high LDL-C level is a major risk factor for CVD, this finding may significantly contribute to disentangling the complex architecture of CVD. Candidate gene screening and the recently developed method for the combined analysis of linkage and association $^{42,43}$ may reveal the genetic variation underlying the QTL.

\section{Acknowledgements}

This study was supported by grants to GP Vogler from the National Institutes of Health, National Heart, Lung, and Blood Institute
(HL55976), to NG Martin and JB Whitfield from the National Heart Foundation of Australia, to NL Pedersen (AG04563 and AG10175) from NIA, to PE Slagboom (98.199) and DI Boomsma (86.083, 88.042 and 90.313) from the Netherlands Heart Foundation.

\section{References}

1 Vogler GP, McClearn GE, Snieder H et al: Genetics and behavioral medicine: risk factors for cardiovascular disease. Behav Med 1997; 22: $141-149$.

2 Hobbs HH, Brown MS, Goldstein JL: Molecular genetics of the LDL receptor gene in familial hypercholesterolemia. Hum Mutat 1992; 1: 445-466.

3 Hansen PS: Familial defective apolipoprotein B-100. Dan Med Bull 1998; 45: 370-382.

4 Brooks-Wilson A, Marcil M, Clee SM et al: Mutations in ABC1 in Tangier disease and familial high-density lipoprotein deficiency. Nat Genet 1999; 22: 336-345.

5 Williams RR, Hopkins PN, Hunt SC et al: Population-based frequency of dyslipidemia syndromes in coronary-prone families in Utah. Arch Intern Med 1990; 150: 582-588.

6 Hamsten A, Iselius L, Dahlen G, de Faire U: Genetic and cultural inheritance of serum lipids, low and high density lipoprotein cholesterol and serum apolipoproteins A-I, A-II and B. Atherosclerosis 1986; 60: 199-208.

7 Beekman M, Heijmans BT, Martin NG et al: Heritabilities of apolipoprotein and lipid levels in three countries. Twin Res 2002; 5: 87-97.

8 Friedlander $\mathrm{Y}$, Leitersdorf $\mathrm{E}$ : Influence of apolipoprotein $\mathrm{E}$ genotypes on plasma lipid and lipoprotein concentrations: 
results from a segregation analysis in pedigrees with molecularly defined familial hypercholesterolemia. Genet Epidemiol 1996; 13: 159-177.

9 Shachter NS: Apolipoproteins C-I and C-III as important modulators of lipoprotein metabolism. Curr Opin Lipidol 2001; 12: 297-304.

10 Kamboh MI, Aston CE, Hamman RF: DNA sequence variation in human apolipoprotein $\mathrm{C} 4$ gene and its effect on plasma lipid profile. Atherosclerosis 2000; 152: 193-201.

11 Walton C, Lees B, Crook D, Godsland IF, Stevenson JC: Relationships between insulin metabolism, serum lipid profile, body fat distribution and blood pressure in healthy men. Atherosclerosis 1995; 118: 35-43.

12 Raclot T, Holm C, Langin D: A role for hormone-sensitive lipase in the selective mobilization of adipose tissue fatty acids. Biochim Biophys Acta 2001; 1532: 88-96.

13 Ishii H, Kim DH, Fujita T, Endo Y, Saeki S, Yamamoto TT: cDNA cloning of a new low-density lipoprotein receptor-related protein and mapping of its gene (LRP3) to chromosome bands 19q12q13.2. Genomics 1998; 51: 132-135.

14 Imperatore G, Knowler WC, Pettitt DJ et al: A locus influencing total serum cholesterol on chromosome 19p: results from an autosomal genomic scan of serum lipid concentrations in Pima Indians. Arterioscler Thromb Vasc Biol 2000; 20: 2651-2656.

15 Ober C, Abney M, McPeek MS: The genetic dissection of complex traits in a founder population. Am J Hum Genet 2001; 69: $1068-1079$

16 Reed DR, Nanthakumar E, North M, Bell C, Price RA: A genomewide scan suggests a locus on chromosome 1q21-q23 contributes to normal variation in plasma cholesterol concentration. J Mol Med 2001; 79: 262-269.

17 Aouizerat BE, Allayee H, Cantor RM et al: A genome scan for familial combined hyperlipidemia reveals evidence of linkage with a locus on chromosome 11. Am J Hum Genet 1999; 65: 397-412.

18 Francke S, Manraj M, Lacquemant C et al: A genome-wide scan for coronary heart disease suggests in Indo-Mauritians a susceptibility locus on chromosome $16 \mathrm{p} 13$ and replicates linkage with the metabolic syndrome on 3q27. Hum Mol Genet 2001; 10: 2751-2765.

19 Broeckel U, Hengstenberg C, Mayer B et al: A comprehensive linkage analysis for myocardial infarction and its related risk factors. Nat Genet 2002; 30: 210-214.

20 Elbein SC, Hasstedt SJ: Quantitative trait linkage analysis of lipidrelated traits in familial type 2 diabetes: evidence for linkage of triglyceride levels to chromosome 19q. Diabetes 2002; 51: 528-535.

21 Abecasis GR, Cherny SS, Cookson WO, Cardon LR: GRR: graphical representation of relationship errors. Bioinformatics 2001; 17: 742-743.

22 Friedewald WT, Levy RI, Fredrickson DS: Estimation of the concentration of low-density lipoprotein cholesterol in plasma, without use of the preparative ultracentrifuge. Clin Chem 1972; 18: $499-502$.

23 Rifai N, Warnick GR, McNamara JR, Belcher JD, Grinstead GF, Frantz ID: Measurement of low-density-lipoprotein cholesterol in serum: a status report. Clin Chem 1992; 38: 150-160.

24 Douglas JA, Boehnke M, Lange K: A multipoint method for detecting genotyping errors and mutations in sibling-pair linkage data. Am J Hum Genet 2000; 66: 1287-1297.

25 Broman KW: Estimation of allele frequencies with data on sibships. Genet Epidemiol 2001; 20: 307-315.

26 Kruglyak L, Daly MJ, Reeve-Daly MP, Lander ES: Parametric and nonparametric linkage analysis: a unified multipoint approach. Am J Hum Genet 1996; 58: 1347-1363.
27 Neale MC, Boker SM, Xie G, Maes HH: Mx: Statistical modeling. Richmond, VA: Department of Psychiatry, Virginia Commonwealth University, 1999.

28 Neale MC: QTL Mapping with sib pairs: the flexibility of $\mathrm{Mx}$; in Spector TD, Snieder H, MacGregor AJ (eds): Advances in twin and sib pair analysis. Greenwich Medical Media, London, 2000.

29 Vogler GP, Tang W, Nelson TL et al: A multivariate model for the analysis of sibship covariance structure using marker information and multiple quantitative traits. Genet Epidemiol 1997; 14: 921-926.

30 Snieder H, van Doornen LJ, Boomsma DI: The age dependency of gene expression for plasma lipids, lipoproteins, and apolipoproteins. Am J Hum Genet 1997; 60: 638-650.

31 Zerba KE, Ferrell RE, Sing CF: Complex adaptive systems and human health: the influence of common genotypes of the apolipoprotein E (ApoE) gene polymorphism and age on the relational order within a field of lipid metabolism traits. Hum Genet 2000; 107: 466-475.

32 Lander E, Kruglyak L: Genetic dissection of complex traits: guidelines for interpreting and reporting linkage results. Nat Genet 1995; 11: 241-247.

33 Rainwater DL, Almasy L, Blangero J et al: A genome search identifies major quantitative trait loci on human chromosomes 3 and 4 that influence cholesterol concentrations in small LDL particles. Arterioscler Thromb Vasc Biol 1999; 19: $777-783$.

34 Klos KL, Kardia SL, Ferrell RE, Turner ST, Boerwinkle E, Sing CF: Genome-wide linkage analysis reveals evidence of multiple regions that influence variation in plasma lipid and apolipoprotein levels associated with risk of coronary heart disease. Arterioscler Thromb Vasc Biol 2001; 21: 971-978.

35 Barton NH, Keightley PD: Understanding quantitative genetic variation. Nat Rev Genet 2002; 3: 11-21.

36 Steinmetz LM, Sinha H, Richards DR et al: Dissecting the architecture of a quantitative trait locus in yeast. Nature 2002; 416: 326-330.

37 Ludwig EH, Hopkins PN, Allen A et al: Association of genetic variations in apolipoprotein B with hypercholesterolemia, coronary artery disease, and receptor binding of low density lipoproteins. J Lipid Res 1997; 38: 1361-1373.

38 Pentikainen MO, Oksjoki R, Oorni K, Kovanen PT: Lipoprotein lipase in the arterial wall: linking LDL to the arterial extracellular matrix and much more. Arterioscler Thromb Vasc Biol 2002; 22: 211-217.

39 Shen Y, Lookene A, Nilsson S, Olivecrona G: Functional analyses of human apolipoprotein CII by site-directed mutagenesis: identification of residues important for activation of lipoprotein lipase. J Biol Chem 2002; 277: 4334-4342.

40 de Graaf J, Hoffer MJ, Stuyt PM, Frants RR, Stalenhoef AF: Familial chylomicronemia caused by a novel type of mutation in the APOE-CI-CIV-CII gene cluster encompassing both the APOCII gene and the first APOCIV gene mutation: APOCII-CIV (Nijmegen). Biochem Biophys Res Commun 2000; 273: 1084-1087.

41 Nishina PM, Johnson JP, Naggert JK, Krauss RM: Linkage of atherogenic lipoprotein phenotype to the low density lipoprotein receptor locus on the short arm of chromosome 19. Proc Natl Acad Sci USA 1992; 89: 708-712.

42 Fulker DW, Cherny SS, Sham PC, Hewitt JK: Combined linkage and association sib-pair analysis for quantitative traits. Am J Hum Genet 1999; 64: 259-267.

43 Posthuma D, Geus EJC, Boomsma DI, Neal MC: Combined linkage and association in Mx. Behav Genet 2003; 153-174. 